\title{
CORRECTION
}

\section{Correction to: Can parental simulation improve neonatal CPR performance? A pilot study}

\author{
Rotem Rephaeli ${ }^{1}$. Dalia Gafanovich ${ }^{2} \cdot$ Irena Shchors $^{3} \cdot$ Giora Weiser $^{1,2}$
}

Published online: 13 January 2022

○) Springer-Verlag GmbH Germany, part of Springer Nature 2021

\section{Correction to: European Journal of Pediatrics (2021) 180:3247-3250 https://doi.org/10.1007/s00431-021-04088-x}

In the original published version of the above article was missing two important notes as follows:

- Rotem Rephaeli and Dalia Gafanovich contributed equally to this manuscript.

- The study was performed as part of the Hebrew University's requirements for the MD degree of Dalia Gafanovich.

The original article has been corrected.

Publisher's Note Springer Nature remains neutral with regard to jurisdictional claims in published maps and institutional affiliations.

The original article can be found online at https://doi.org/10.1007/ s00431-021-04088-x.

Giora Weiser gioraweiser@gmail.com

1 Pediatric Emergency Department, Shaare Zedek Medical Center, 12 Bait St, 9103210 Jerusalem, Israel

2 The Faculty of Medicine, Hebrew University of Jerusalem, Jerusalem, Israel

3 Neonatal Intensive Care Unit, Shaare Zedek Medical Center, Jerusalem, Israel 